\title{
Avaliação In Situ da Associação do Verniz Fluoretado AO LASER DE ER:YAG E AO LASER DE ND:YAG NA PERMEABILIDADE Da Dentina Radicular ERodida
}

Dissertação apresentada à Faculdade de Odontologia de Ribeirão Preto da Universidade de São Paulo, para obtenção do título de Mestre em Ciências.

Programa: Odontopediatria

Área de concentração: Odontopediatria

Orientadora: Profa. Dra. Silmara Aparecida Milori Corona

Ribeirão Preto 
Autorizo a reprodução e divulgação total ou parcial deste trabalho, por qualquer meio convencional ou eletrônico, para fins de estudo e pesquisa, desde que citada a fonte.

Nemezio, Mariana Alencar.

Avaliação in situ da associação do verniz fluoretado ao laser de Er:YAG e ao laser de Nd:YAG na permeabilidade da dentina radicular erodida. Ribeirão Preto, 2013.

52p.: il, $30 \mathrm{~cm}$.

Dissertação de Mestrado apresentada à Faculdade de Odontologia de Ribeirão Preto da Universidade de São Paulo. Área de concentração: Odontopediatria.

Orientadora: Corona, Silmara Aparecida Milori.

1. Erosão. 2. Laser de Er:YAG. 3. Laser de Nd:YAG.

4. Verniz fluoretado. 5. Dentina radicular. 
FolHa de AprovaçÃo

Nemezio, MA. Avaliação In Situ da Associação do Verniz Fluoretado ao Laser de Er:YAG e ao Laser de Nd:YAG na Permeabilidade Da Dentina Radicular Erodida

Dissertação apresentada à Faculdade de Odontologia de Ribeirão Preto da Universidade de São Paulo para obtenção do Título de Mestre em Ciências. Programa: Odontopediatria. Área de concentração: Odontopediatria.

Aprovado em: 1

Banca Examinadora

Prof. Dr.

Instituição:

Julgamento: Assinatura:

Prof. Dr.

Instituição:

Julgamento: Assinatura:

Prof. Dr. Instituição: 


\section{DAdOS CURRICULARES}

Nascimento 25 de julho de 1986 - Maceió/AL

Filiação Luiz Marcos Nemezio

Rosilea Alencar Gouveia Nemezio

2005-2010 Curso de Graduação.

Universidade Federal de Alagoas (UFAL)

2011-2012 Curso de aperfeiçoamento em Atendimento Odontológico a Pacientes Especiais.

Faculdade de Odontologia de Ribeirão Preto USP.

2011-2013 Especialização em Odontopediatria - Associação Odontológica de Ribeirão Preto (AORP)

2011-2013 Curso de pós-graduação (Mestrado) em Odontologia.

Área de concentração: Odontopediatria

Faculdade de Odontologia de Ribeirão Preto/USP 


\section{Dedicatória}


Dedico este TRABALHo,

Deus, por ter me permitido concluir este trabalho.

Aos meus pais, Luiz Marcos Nemezio e Rosilea Alencar Gouveia Nemezio, pelo exemplo de dedicação, amor e união. Apesar de toda a saudade que a distância nos proporcionou, consegui crescer profissionalmente. Muito obrigada pelo apoio em todos os momentos da minha vida!

À minha irmã, Maria Eliza Alencar Nemezio, pela amizade, companheirismo e amor. Como eu costumo dizer, ela é minha segunda mãe. Obrigada pelos conselhos nem sempre agradáveis de escutar, mas extremamente necessărios. Sem você, não teria chegado até aqui.

À minha orientadora, Professora Dr. Silmara Aparecida Milori Corona. Não sei como agradecer a uma pessoa tão especial, que me mostrou um modo diferente de enfrentar a vida. A senhora me fez acreditar que eu era capaz. Muito obrigada! 
Agradecimentos Especiais 
Aos meus familiares, pelo amor e união. Por vocês, todas as dificuldades são vencidas e as alegrias compartilhadas. Sem vocês, não seria nada.

À minha orientadora, Professora Dra. Silmara Aparecida Milori Corona. Sou muita grata a Deus por ter colocado a senhora em minha vida. Meus sinceros agradecimentos pelos ensinamentos, carinho e dedicação.

Às amigas Ana Caroline Fumes, Denise de Souza Matos, Katharina Morant Holanda de Oliveira, Priscilla Coutinho Romualdo, Silvana aparecida Fernandes Polizeli, Daniele Luca Longo, Larissa Nogueira Soares Ribeiro e Driely Barreiros de Oliveira, pela família formada durante o mestrado. Obrigada por tudo.

Às professoras de Odontopediatria da Universidade Federal de Alagoas, Maria Dânia Holanda Tenório, Patrícia Batista Lopes do Nascimento e Lucineide de Melo Santos, por me ensinarem a amar o que eu faço.

Ao professor de Ortodontia da Universidade Federal de Alagoas, Jovenildo Wanderley Santos, pela dedicação, incentivo, amizade, conselhos e por mostrar que, com dedicação, podemos realizar nossos sonhos.

Aos amigos Renata Siqueira Scatolin, Rodrigo Valério, Daniel Galafassi, TaísaLepri, e Sandra Chiga Carvalho, pela amizade e ajuda na execução deste trabalho.

Ao Professor Doutor Rodrigo Galo, pela amizade, paciência, disponibilidade, auxillio e orientação na anălise estatística.

Às amigas Danielle Torres Azevedo e Giselle de Angelo S. Leite, por todo o apoio e toda a amizade. Vocês são pessoas iluminadas, amigas maravilhosas. Muito obrigada!

À Professora Doutora Maria Cristina Borsato, pelos ensinamentos e carinho. 
Agradecimentos 
À Faculdade de Odontologia de Ribeirão Preto, da Universidade de São Paulo, na pessoa do atual diretor, Professor Doutor Valdemar Mallet da Rocha Barros, e a ViceDiretora, Professora Doutora Léa Assed Bezerra da Silva.

À Coordenação do Curso de Pós-Graduação da Faculdade de Odontologia de Ribeirão Preto da Universidade de São Paulo, na pessoa do atual Professor Doutor Arthur Belém Novaes Júnior.

À Coordenação do Curso de Pós-Graduação da Faculdade de Odontologia de Ribeirão Preto da Universidade de São Paulo, área de concentração em Odontopediatria, na pessoa da atual Professora Doutora Léa Assed Bezerra da Silva e do Vice-Coordenador, Professor Doutor Paulo Nelson Filho.

Ao CNPq (Proc. 472661/2010-8), pela concessão de Auxîlio Pesquisa, que permitiu a execução deste trabalho.

À CAPES (Coordenação de Aperfeiçoamento de Pessoal de Nivel Superior), pela bolsa concedida.

À Professora Doutora Regina Guenka Palma-Dibb, por disponibilizar o laser de Nd:YAG, utilizado no presente estudo.

Ao Professor Doutor Vanderley Bagnato, do Instituto de Física de São Carlos (IFSC-USP), por permitir o uso do laser de Er:YAG.

Aos voluntários que participaram deste trabalho; sem eles, a realização deste trabalho não seria possível.

À Professora Doutora Sandra Y. F. Alves, pelos ensinamentos no início do mestrado. 
Aos funcionários do Departamento de Clínica Infantil, Odontologia Preventiva e Social da Faculdade de Odontologia de Ribeirão Preto: Filomena L. Placcit, Micheli Cristina L. Rovanholo, Matheus M. Zanela, Francisco Wanderley G. de Paula e Silva, Carolina P. T. Mantovani, Marco Antônio dos Santos, Marilia P. Lucisano, Carmo Eurípedes T. Barretto, Nilza Letícia Magalhães, Fátima A. Rizoli, Fátima A. Jacinto Daniel e Renata A. Fernandes. Obrigada pela disponibilidade, paciência e ajuda.

À Patrícia Marchi, técnica do Departamento Odontologia Restauradora da Faculdade de Odontologia de Ribeirão Preto - USP, pela colaboração e pela disposição na execução da parte experimental deste trabalho.

Aos docentes do departamento de Clínica Infantil e Social da Faculdade de Odontologia de Ribeirão Preto, São Paulo, Professoras Doutoras Aldevina Campos de Freitas, Alexandra Mussolino de Queiroz, Andiara De Rossi, Kranya Victoria Díaz Serrano, Léa Assed Bezerra da Silva, Maria Cristina Borsatto, Raquel Assed Bezerra da Silva, Sada Assed, Maria Bernadete Sasso Stuani, Mírian Aiko Nakane Matsumoto, Maria da Conceição Pereira Saraiva e aos Professores Doutores Paulo Nelson Filho, Adîlson Tomasin, Fábio Lourenço Romano e José Tarcísio Lima Ferreira, pelos ensinamentos e atenção.

Aos alunos do Curso de Pós-graduação em Odontopediatria, Giselle Leite, Danielle Azevedo, Késsia Mesquita, Fernanda Santos, Marina Sena, Marta Contente, Cíntia Almeida, Rodrigo Valério e Camila Scatena, pela amizade, companhia diária e garantia de muitos sorrisos.

Às amigas de mestrado, Ana Caroline Fumes, Denise Matos, Katharina Morant, Priscilla Romualdo, Karina Pieroni, Danielly Ferreira, Danielly Longo, Silvana Polizeli, Driely Oliveira, Larissa Ribeiro, Talita Prates, Leticia Bignardi e Bárbarra Jareta, pela amizade, carinho e ajuda.

À Professora de Português, Ana Rachel Cavalieri Bittar, pela correção do texto. 
Resumo 
RESUMO

Nemezio, M.A. Avaliação In Situ da Associação do Verniz Fluoretado ao Laser de Er:YAG e ao Laser de Nd:YAG na Permeabilidade da Dentina Radicular Erodida. Ribeirão Preto, 2013. 52p. [Dissertação de Mestrado]. Ribeirão Preto: Faculdade de Odontologia de Ribeirão Preto da Universidade de São Paulo; 2013.

O objetivo do presente estudo foi avaliar in situ o efeito da associação do verniz fluoretado ao laser de Er:YAG e ao laser Nd:YAG na permeabilidade da dentina radicular erodida. Quarenta e oito fragmentos de dentina radicular bovina, com dimensões $2 \times 2 \times 2 \mathrm{~mm}$, foram submetidos a um desafio erosivo inicial com ácido cítrico $(0,3 \%, \mathrm{pH} 3,2)$, por duas horas, sob agitação e armazenados em saliva artificial por vinte e quatro horas. Posteriormente, os espécimes foram divididos em relação aos tratamentos: verniz fluoretado e não fluoretado e subdivididos conforme a irradiação: laser de Er:YAG $(100 \mathrm{~mJ}, 3 \mathrm{~Hz})$, laser de Nd:YAG $(70 \mathrm{~mJ}$, $15 \mathrm{~Hz}$ ) e não irradiado. Após um período de lead in (2 dias), os voluntários ( $n=8)$ utilizaram dispositivos palatinos contendo três espécimes que foram submetidos a desafios erosivos ex vivo, quatro vezes ao dia, com ácido cítrico $(0,3 \%, \mathrm{pH} 3,2)$, durante $90 \mathrm{~s}$, por cinco dias. $\mathrm{Na}$ primeira fase do experimento, metade dos voluntários utilizou dispositivos contendo fragmentos tratados com verniz fluoretado, verniz fluoretado + laser de Er:YAG e verniz fluoretado + laser de Nd:YAG. A outra metade utilizou verniz não fluoretado, verniz não fluoretado + laser de Er:YAG e verniz não fluoretado + laser de Nd:YAG. Depois de um período de wash-out (15 dias), os voluntários foram cruzados quanto aos tratamentos, caracterizando um experimento cross-over $2 \times 2$. Ao final de cada fase experimental, a permeabilidade dentinária foi avaliada. A ANOVA dois critérios e o teste complementar de Duncan revelaram uma diferença significativa entre os espécimes tratados com o verniz fluoretado $(p=0,005)$, verniz fluoretado + laser de Er:YAG $(p=0,014)$ e verniz fluoretado + laser de Nd:YAG $(p=0,025)$, em comparação aos tratados com verniz não fluoretado. Observou-se que, independentemente da associação aos lasers (Er:YAG ou Nd:YAG), o verniz fluoretado foi capaz de promover a redução da permeabilidade da dentina radicular erodida. Não se observou efeito adicional com a associação dos tratamentos.

Palavras-chaves: Erosão, Laser de Er:YAG, Laser de Nd:YAG, Verniz fluoretado, Dentina radicular. 


\section{Abstract}




\section{Abstract}

Nemezio, M.A. In Situ Evaluation of Associating the Fluoride Varnish to Er:YAG or Nd:YAG Laser at permeability of eroded root dentin. Ribeirão Preto, 2013. 52p. [Dissertação de Mestrado]. Ribeirão Preto: Faculdade de Odontologia de Ribeirão Preto da Universidade de São Paulo; 2013.

The present study aimed to evaluate in situ the effect of associating the fluoride varnish to Er:YAG or Nd:YAG laser at permeability of eroded root dentin. Forty-eight specimens of bovine root dentin $(2 \times 2 \times 2 \mathrm{~mm})$ were subjected to initial erosive challenge with citric acid (0.3\%, pH 3.2), for 2 hours under agitation and stored at artificial saliva, at $37^{\circ} \mathrm{C}$, for 24 hours, followed by a remineralization period in artificial saliva. After that, specimens were divided according to the treatment: fluoride varnish and non-flouride varnish, and subdivided according to the irradiation: Er:YAG laser $(100 \mathrm{~mJ}, 3 \mathrm{~Hz}), \mathrm{Nd}: Y A G$ laser $(70 \mathrm{~mJ}, 15 \mathrm{~Hz})$ and non-irradiated. After a lead-in period ( 2 days), 8 volunteers $(n=8)$ wore a palatal device containing 3 specimens that was subjected to erosive challenges ex vivo, four times a day with citric acid (0.3\%, pH3.2), for 90s, during 5 days. At the first experimental phase, half of volunteers wore devices containing specimens treated with fluoride varnish, fluoride varnish + Er:YAG laser and fluoride varnish + Nd:YAG laser, and the other half wore the specimens treated with non-fluoride varnish, non-fluoride varnish + Er:YAG laser and non-flouride varnish + Nd:YAG laser. After a wash-out period (15 days), volunteers were crossed to different treatment, characterizing a $2 \times 2$ cross-over experiment. At the end of each experimental phase, the dentinal permeability was evaluated. Two-way ANOVA and Duncan's test revealed a significant difference between specimens treated with fluoride varnish $(p=0,005)$, fluoride varnish + Er:YAG laser $(p=0,014)$ and fluoride varnish $+N d: Y A G$ $(p=0,025)$ compared to specimens treated with no-fluoride varnish. It was observed that regardless of association to laser (Er:YAG or Nd:YAG), fluoride varnish was able to promote, in situ, the reduction of permeability of eroded root dentin, but no additional effect was observed when the treatments were associated.

Keywords: erosion, Er:YAG laser, Nd:YAG laser, fluoride varnish, root dentine 
Sumário 
1. INTRODUÇÃO

2. PROPOSIÇÃO

3. MATERIAL E MÉTODO

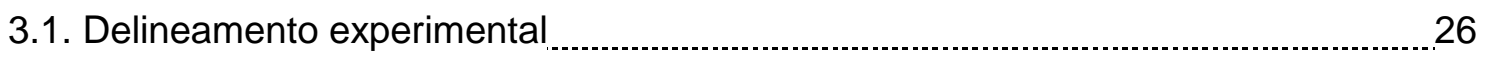

3.2. Seleção dos voluntários …………………………………………………….... 26

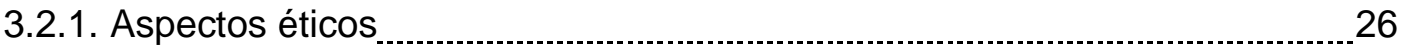

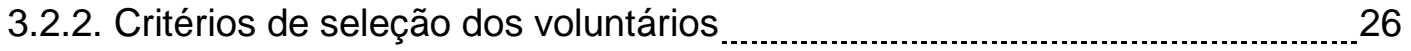

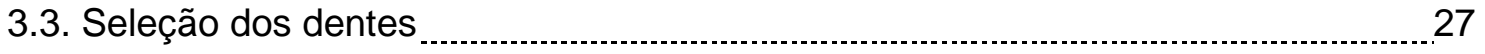

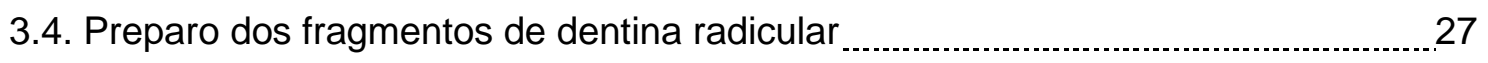

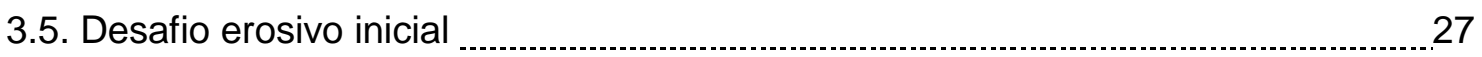

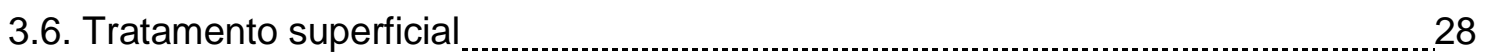

3.7. Confecção dos dispositivos e montagem dos fragmentos nos dispositivos

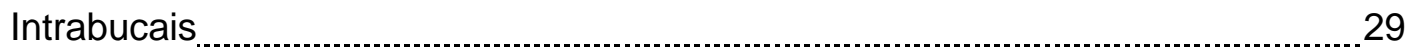

3.8. Fase intrabucal

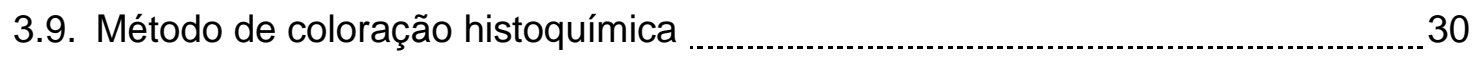

3.10. Avaliação da permeabilidade

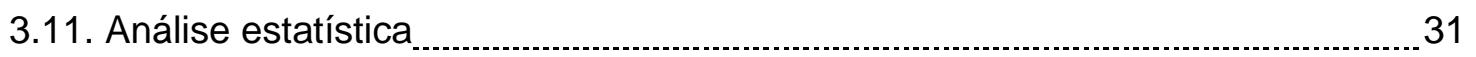

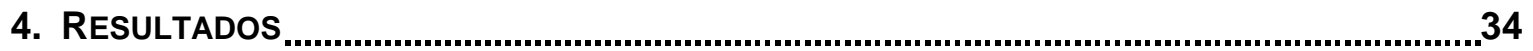

5. DISCUSSÃO

6. CoNCLUSÃO

REFERÊNCIAS

ANEXO 


\section{Introdução}




\section{INTRODUÇÃO}

A palavra erosão é derivada do verbo eroděre, em latim, que significa uma destruição progressiva, provocada por processos químicos ou eletrolíticos (Imfeld, 1996). Na odontologia, o termo erosão é utilizado para descrever o resultado físico de uma patologia crônica e localizada, caracterizada pela perda irreversível da estrutura dentária em decorrência de uma exposição ácida, sem envolvimento bacteriano, que pode ser causada por fatores intrínsecos e extrínsecos (Eccles; Jenkins, 1974; Imfeld, 1996).

A erosão intrínseca é resultado do contato do ácido gástrico com os substratos dentários (Imfeld, 1996) que ocorrem durante episódios de vômitos recorrentes, regurgitação ou refluxo gastroesofágico de origem psicossomática, como a bulimia e anorexia (Scheutzel, 1996), ou somática, devido à gravidez, ao alcoolismo (Smith; Robb, 1989) e problemas gastrointestinais, com recorrentes quadros de refluxos, regurgitações e vômitos (Gudmundsson et al., 1995).

A erosão extrínseca é provocada por ácidos exógenos (Imfeld, 1996), que podem ter origem na dieta (Lussi et al., 2004; Bartlett, 2005; Bartlett et al., 2011; Lussi et al., 2012), no uso de medicamentos (Lussi et al., 2012; McCarthy, 2012), drogas ilícitas (McCarthy, 2012) e em fatores ocupacionais (McCarthy, 2012). Dentre essas causas, a principal responsável pelo aumento da prevalência da erosão é o consumo elevado e frequente de bebidas ácidas (Amaechi; Higham, 2005). Para se evitar a erosão extrínseca, recomenda-se que bebidas ácidas sejam ingeridas por meio de canudos, o que diminui o contato entre os ácidos e o elemento dental (Zero, 1996; Millward et al., 1997). Refrigerantes, sucos cítricos, isotônicos esportivos e algumas bebidas alcoólicas têm, de acordo com a literatura, alto potencial erosivo (Zero, 1996)

Os tecidos dentais apresentam composições distintas, o que faz com que os agentes erosivos tenham diferentes efeitos sobre o esmalte e a dentina (Shellis et al., 2010). O esmalte é composto por mineral ( $85 \%$ em volume), na forma de cristais de hidroxiapatita ou fluorapatita, organizados em prismas, e a dentina possui componente inorgânico (47\% de apatita), orgânico (33\% de colágeno) e água (20\%) (Magalhães et al., 2009). Inicialmente, o processo erosivo ocorre de maneira semelhante no esmalte e na dentina, até o momento no qual as fibras colágenas tornam-se expostas, com posterior redução da erosão no tecido dentinário. As fibras 
colágenas atuam como uma barreira mecânica à perda mineral, além de possuírem capacidade tampão (Kleter et al., 1994; Hara et al., 2005; Hiraishi et al., 2011).

A erosão no substrato dentinário é caracterizada por diferenças na resistência ácida, quando se compara a dentina peritubular com a intertubular. A dentina peritubular é totalmente dissolvida, o que causa o aumento do diâmetro dos túbulos dentinários (Meurman et al., 1991) e, consequentemente, da permeabilidade (Prati et al., 2003), enquanto a dentina intertubular apresenta maior rugosidade e porosidade (Meurman; ten Cate, 1996). Esse processo, que pode deixar os dentes sensíveis a estímulos externos (Meurman; ten Cate, 1996), justifica o crescente interesse no estudo da erosão dentinária.

A hipersensibilidade dentinária é definida como uma dor aguda e de curta duração, resultante da exposição da dentina, após o desgaste do esmalte ou cemento, expondo os túbulos dentinários a estímulos mecânicos, químicos, térmicos ou osmóticos (Orchardson; Collins 1987; Addy, 1992). Os dentes sensíveis, quando comparados a dentes não sensíveis, apresentam oito vezes mais túbulos e possuem diâmetros duas vezes maiores (Absi et al., 1987), o que causa o aumento do fluxo do fluido no interior dos túbulos. Dessa forma, opta-se por controlar a progressão das lesões de erosão por meio do emprego de agentes obliteradores dos túbulos dentinários (Sauro et al., 2006; Hsu et al., 2006), que interferem na condução hidrodinâmica da dentina (Bartold, 2006).

Um dos agentes dessensibilizantes mais utilizados na clínica odontológica para oclusão dos túbulos dentinários é o verniz fluoretado profissional. Com a aplicação desse verniz, ocorre a criação de uma barreira na superfície do dente, por meio da precipitação do fluoreto de cálcio $\left(\mathrm{CaF}_{2}\right)$, que bloqueia a entrada dos túbulos dentinários, reduzindo a permeabilidade $\mathrm{e}$, consequentemente, a sintomatologia dolorosa (Ritter, 2006). O verniz fluoretado profissional também é uma opção terapêutica para o controle da erosão no substrato dentinário (Magalhães et al., 2008; Magalhães et al., 2010), porém seu papel na erosão dental ainda é questionado e discutido, pois a deposição mineral $\left(\mathrm{CaF}_{2}\right)$ pode ser dissolvida pela maioria das bebidas ácidas (Magalhães et al., 2008; Magalhães et al., 2010).

Assim, a busca por um tratamento mais efetivo no controle das lesões de erosão responsáveis pelo desencadeamento clínico da hipersensibilidade dentinária cervical tem impulsionado o desenvolvimento de novas tecnologias, como o emprego do laser, que é uma luz monocromática, colimada, coerente, nomeada de 
acordo com o meio ativo pelo qual é estimulada (Stabholz et al., 2003). Esse meio pode ser sólido, líquido ou gasoso, resultando em diferentes comprimentos de onda, que possuem diferentes formas de interação com os tecidos (Parker, 2007; Martens, 2011).

O laser de Er:YAG foi o primeiro aprovado pela Food and Drug Administration (em 1997) para aplicação nos tecidos dentários (Van, 2004). O laser Er:YAG possui como meio ativo uma granada de ítrio-alumínio dopada com íons érbio, que, uma vez estimulado, emite um comprimento de onda de $2.940 \mathrm{~nm}$, que coincide com os picos de absorção da água e da hidroxiapatita. A irradiação emitida é fortemente absorvida pela água e induz a uma rápida elevação de temperatura e pressão, ocasionando a remoção do tecido aquecido por meio de ablação (Hibst; Keller 1989; Hoke et al., 1990; Aoki et al., 1996). Quando é utilizado em parâmetros subablativos e no modo desfocado, o laser de Er:YAG não é capaz de promover a remoção da estrutura dentária (Carvalho et al., 2005); além disso, ele pode provocar a fusão da dentina através de uma obliteração parcial (Aranha; Eduardo, 2012), permitindo uma diminuição do diâmetro dos túbulos (Aranha; Eduardo, 2012) e da permeabilidade dentinária (Aranha et al., 2005; Aranha; Eduardo, 2012).

O laser de Nd:YAG foi desenvolvido por Johnson, em 1961. O comprimento de onda de emissão desse tipo de laser é de 1.064 nm e por isso é pouco absorvido pela hidroxiapatita e pela água, emitindo um comprimento de onda próximo ao infravermelho (Johnson, 1961; Parker, 2007). O laser de Nd:YAG pode induzir a oclusão dos túbulos dentinários por meio da fusão e ressolidificação da dentina, principalmente na dentina peritubular (Magalhães et al., 2004; Gholami et al., 2011), o que ocasiona a diminuição do diâmetro dos túbulos (Aranha et al., 2005; Gholami et al., 2011). Essas alterações também foram notadas na dentina erodida (Naylor et al., 2006) na qual o laser de Nd:YAG mostrou-se capaz de reduzir a permeabilidade dentinária (Aranha et al., 2005).

A ação do laser de Er:YAG (Schwarz et al., 2002; Birang et al., 2007) e do laser de Nd:YAG no controle da hipersensibilidade dentinária já foi demonstrada previamente (Birang et al., 2007), todavia o real mecanismo pelo qual ocorre essa redução da sintomatologia dolorosa ainda se mantém em debate. Tem sido descrito que o laser de Nd:YAG pode ser capaz de promover a fusão e ressolidificação da smear layer e dos túbulos dentinários, promovendo o bloqueio da despolarização das fibras nervosas, por meio da interferência na bomba de sódio e potássio, o que 
resultaria em analgesia pulpar (Sunakawa et al., 2000; Stabholz et al., 2004). Da mesma maneira, a capacidade de redução da sintomatologia dolorosa após o tratamento com o laser de Er:YAG ocorre pela obstrução ou estreitamento dos túbulos (Farmakis et al., 2012), o que pode promover a diminuição do volume do fluido dentinário por meio da evaporação das suas camadas superficiais (Schwarz et al., 2002).

Assim, foi proposta a realização deste estudo devido à possibilidade de ocorrer efeito complementar e prolongado entre os tratamentos e à ausência de estudos in situ que analisam o efeito da associação do verniz fluoretado ao laser de Er:YAG e Nd:YAG na permeabilidade da dentina radicular erodida após sucessivos desafios ácidos. 
Proposição 


\section{ProposiçÃo}

O objetivo do presente estudo foi avaliar in situ o efeito da associação do verniz fluoretado profissional ao laser de Er:YAG e ao laser de Nd:YAG na dentina radicular após sucessivos desafios erosivos com ácido cítrico por meio da análise de permeabilidade. 
Material e Método 


\section{Material e Método}

\subsection{Delineamento experimental}

Este estudo in situ, cross-over 2x2, duplo cego, foi realizado após um período de lead-in de 2 dias, em duas fases de cinco dias cada, com intervalo de quinze dias entre elas (wash-out). Os fatores em estudo foram tratamento com verniz em 2 níveis (fluoretado e não fluoretado) e irradiação com laser em 3 níveis (Er:YAG, $\mathrm{Nd}$ :YAG e não irradiado-controle). A amostra do experimento foi composta por 48 fragmentos de dentina radicular bovina, divididos aleatoriamente entre 8 voluntários. Cada voluntário foi considerado um bloco estatístico. A variável de resposta foi obtida por meio da análise da permeabilidade em porcentagem. A figura 1 mostra o delineamento experimental deste experimento.

\subsection{Seleção dos voluntários}

\subsubsection{Aspectos éticos}

O presente estudo foi aprovado pelo Comitê de Ética e Pesquisa da Faculdade de Odontologia de Ribeirão Preto-SP/Plataforma Brasil (processo $n^{\circ}$ 92.188). Os voluntários foram informados quanto à metodologia, riscos e benefícios da pesquisa e que poderiam desistir em qualquer fase de execução. Aqueles que concordaram em participar da pesquisa assinaram o "Termo de Consentimento Livre e Esclarecido".

\subsubsection{Critérios de seleção dos voluntários}

Para o estudo, foram selecionados oito voluntários de ambos os gêneros, residentes na cidade de Ribeirão Preto-SP, com idade entre 18 e 38 anos, com fluxo salivar estimulado entre 1,6 e 2,3 mL/min, ausência de lesão de cárie ativa e de lesões não cariosas. Os critérios de exclusão dos voluntários foram uso de medicamentos que interferisse na salivação, tratamento por radioterapia ou quimioterapia, gravidez ou lactantes, alta atividade de cárie ou doença periodontal, doenças sistêmicas ou distúrbios de ordem digestiva e uso de prótese ou aparelhos ortodônticos. 


\subsection{Seleção dos dentes}

Para a realização do estudo, foram selecionados incisivos bovinos recémextraídos, armazenados em solução de timol 0,1\% a $4^{\circ} \mathrm{C}$ (Dominici et al., 2001). O tecido periodontal foi removido com curetas periodontais (Neumar, São Paulo, SP, Brasil) e limpos com pasta de pedra-pomes (S.S. White, Rio de Janeiro, RJ, Brasil) e água, com auxílio de taça de borracha (MICRODONT, São Paulo, SP, Brasil) montada em turbina de baixa rotação (Dabi Atlante, Ribeirão Preto, SP, Brasil). Os dentes foram avaliados por estereomicroscópio (Leica S6 D Stereozoom, Leica Mycrosystems AG, Suíça), utilizando-se o aumento de 40x. Descartaram-se os dentes com anomalias ou trincas.

\subsection{Preparo dos fragmentos de dentina radicular}

Foram obtidos do terço cervical de cada raiz dois fragmentos com dimensões 2x2x2 mm, cortados com um disco flexível diamantado (15HC, Buehler, Alemanha), montado em cortadeira elétrica de precisão (Isomet 1000, Buehler, Alemanha) refrigerada à água. Após a checagem das dimensões com o paquímetro digital (Mitutoyo Sul-americana, Suzano, SP, Brasil), a camada de cemento dos espécimes foi removida com lixas abrasivas \#1200 (Saint-Gobain Abrasivos Ltda, Igarassú, Pernambuco, Brasil) (Ganss et al., 2000).

Duas aplicações de esmalte para unha (Colorama, São Paulo, SP, Brasil), foram realizadas nas faces mesial, distal e lingual do fragmento, de maneira que apenas a superfície vestibular ficou exposta aos desafios ácidos (Scatolin et al., 2012).

Por fim, os espécimes foram submetidos à esterilização com óxido de etileno (Toro et al., 2000) e uma nova análise para verificar a presença de falhas na estrutura da dentina foi realizada com 0 auxílio do estereomicroscópio. Selecionaram-se, então, 48 fragmentos dentinários.

\subsection{Desafio Erosivo Inicial}

Os fragmentos foram imersos em $20 \mathrm{~mL}$ de ácido cítrico $(0,3 \%$ e pH 3,2), à temperatura ambiente e levados à máquina de agitação (CT155, Cientec, 
Piracicaba, SP, Brasil) por 2 horas (Vanuspong et al., 2002), com velocidade de agitação de 50 rpm. Após o desafio erosivo inicial, os espécimes foram enxaguados por 10 segundos com água deionizada e armazenados em $10 \mathrm{~mL}$ de saliva artificial, por um período de 24 horas, a uma temperatura de $37^{\circ} \mathrm{C}$. A saliva utilizada foi similar à descrita por Mcknight-Hanes e Whitford (1992) e modificada por Amaechi et al. (1999), que apresentava em $1000 \mathrm{~mL}$ de solução aquosa a seguinte composição: metilhidroxibenzoato $(2,0 \mathrm{~g})$, carboximetilcelulose $(10,0 \mathrm{~g}), \mathrm{KCl}(0,65 \mathrm{~g}), \mathrm{MgCl}_{2} \cdot 6 \mathrm{H}_{2} \mathrm{O}$ $(0,059 \mathrm{~g}), \mathrm{CaCl}_{2} \cdot 2 \mathrm{H}_{2} \mathrm{O}(0,166 \mathrm{~g}), \mathrm{K}_{2} \mathrm{HPO}_{4}(0,804 \mathrm{~g})$ e $\mathrm{KH}_{2} \mathrm{PO}_{4}(0,326 \mathrm{~g})$.

\subsection{Tratamento Superficial}

Após a formação das lesões iniciais de erosão, os espécimes foram divididos de modo aleatório, de acordo com os tratamentos empregados: verniz fluoretado ou verniz não fluoretado. Os espécimes foram subdivididos conforme a irradiação: laser de Er:YAG (100mJ, $3 \mathrm{~Hz})$, laser de Nd:YAG $(70 \mathrm{~mJ}, 15 \mathrm{~Hz})$ e não irradiado.

Inicialmente, foi realizada a aplicação do verniz (fluoretado ou não fluoretado), com o auxílio de um microbrush (Viagodent AS Indústria e Comércio, RJ, Brasil), na superfície vestibular dos espécimes. Um minuto após a aplicação do verniz, os espécimes foram armazenados individualmente em potes plásticos e imersos em saliva artificial por 24 horas, a uma temperatura de $37^{\circ} \mathrm{C}$. Após esse período, a camada de verniz foi cuidadosamente removida com uma lâmina de bisturi (Delbem et al., 2007) $n^{\circ} 15$ (Lamed $\AA$, Uberaba, MG, Brasil). A tabela 1 mostra a composição dos vernizes empregados.

Para os espécimes que receberam irradiação com o laser de Er:YAG (Twin Light, Fidelis plus Fotona, Ljubljana, Eslovênia), foi empregado um comprimento de onda de $2.940 \mathrm{~nm}$, no modo não contato, desfocado a uma distância de $17 \mathrm{~mm}$ da amostra, energia de 100mJ, 3Hz de frequência (Birang et al., 2007), diâmetro de 835 $\mu \mathrm{m}$ e densidade de energia por pulso de $12,8 \mathrm{~J} / \mathrm{cm}^{2}$. A irradiação foi realizada sob refrigeração, utilizando-se um spray de água 1,5 mL/min (Colucci et al., 2009). O tempo para irradiar cada espécime foi de aproximadamente 10 segundos.

Para os espécimes que receberam irradiação com o laser de $\mathrm{Nd}$ :YAG (SmartFile, Deka, Firenze, Itália), foram utilizados os seguintes parâmetros: 1.0W, $15 \mathrm{~Hz}$ (Birang et al., 2007), 70mJ, fibra de quartzo de $300 \mu \mathrm{m}$ de diâmetro em um comprimento de onda de $1064 \mathrm{~nm}$, densidade de energia por pulso de $99 \mathrm{~J} / \mathrm{cm}^{2}$, no 
modo contato, sem refrigeração, de maneira uniforme, de modo que toda a superfície fosse irradiada. A cada 3 irradiações, a fibra óptica do laser de Nd:YAG era clivada. Os grupos que receberam apenas aplicação do verniz (fluoretado e não fluoretado) foram mantidos em umidade relativa a uma temperatura de $4^{\circ} \mathrm{C}$, enquanto as outras amostras foram irradiadas.

Tabela 1. Tipo de Verniz

\begin{tabular}{|c|c|c|c|}
\hline VERNIZ & COMPOSIÇÃO & LOTE & FABRICANTE \\
\hline $\begin{array}{l}\text { Fluoretado } \\
\text { (Duraphat@) }\end{array}$ & $\begin{array}{l}\text { Fluoreto de Sódio a 5\%, } \\
22.600 \text { ppm de flúor em } \\
\text { base de resina, álcool } \\
33,1 \% \text {, aromatizante } \\
\text { resina natural, sacarina, } \\
\text { cera e aromatizante } \\
(\mathrm{pH}=4.5) .\end{array}$ & 08.09-02 & $\begin{array}{c}\text { Colgate-Palmolive, } \\
\text { SP, Brasil }\end{array}$ \\
\hline $\begin{array}{c}\text { Sem Flúor } \\
\text { (Fórmula \& Ação®) }\end{array}$ & $\begin{array}{c}\text { Polímero acrílico, xilitol, } \\
\text { espessante, } \\
\text { aromatizante, } \\
\text { conservante, água } \\
\text { deionizada, resina } \\
\text { hidrogenada. }\end{array}$ & $211828 / 1$ & $\begin{array}{c}\text { Fórmula \& Ação, } \\
\text { SP, Brasil }\end{array}$ \\
\hline
\end{tabular}

\subsection{Confecção dos dispositivos e montagem dos fragmentos nos dispositivos intrabucais}

Foram confeccionados dispositivos palatinos em resina acrílica autopolimerizável. Na superfície externa dos dispositivos, foi preparado um nicho medindo $15 \times 5 \times 3 \mathrm{~mm}$, para a fixação dos fragmentos de dentina. A fixação foi realizada com cera e os fragmentos foram posicionados de acordo com um sorteio aleatório.

Os dispositivos foram verificados quanto à sua adaptação no interior da cavidade bucal, e, se necessário, ajustes foram realizados. 


\subsection{Fase intrabucal}

Os voluntários foram instruídos a utilizar a escova dental (Oral-B Indicator 35, Gillette do Brasil Ltda., Manaus, Amazonas, Brasil) e o dentifrício (Colgate ${ }^{\circ}$ Máxima Proteção Anticáries, Colgate-Palmolive, Osasco, São Paulo, Brasil) fornecidos pelos pesquisadores dois dias antes do início do uso dos dispositivos palatinos (lead in). Vinte e quatro horas após a instalação dos dispositivos, os desafios erosivos foram iniciados. Os voluntários utilizaram o aparelho das 8 h às 17 h (West et al., 1998), que foi removido apenas para a alimentação e higiene oral (4 vezes ao dia, 1 hora por refeição) (West et al., 1998). Os dispositivos, quando removidos, eram mantidos em umidade relativa, em um recipiente fechado com gaze umedecida (Turssi et al., 2010).

$\mathrm{Na}$ primeira fase do experimento, metade dos voluntários utilizou fragmentos contendo verniz fluoretado, verniz fluoretado + laser de Er:YAG e verniz fluoretado + laser de Nd:YAG. A outra metade utilizou verniz não fluoretado, verniz não fluoretado + laser de Er:YAG e verniz não fluoretado + laser de Nd:YAG.

Os desafios erosivos foram realizados com ácido cítrico a 0,3\% e pH 3,2 (Vanuspong et al., 2002), 4 vezes por dia (9h, 11h, 13h e 15h ), conforme descrito por West et al. (1998), ex vivo pela imersão do dispositivo palatino em $50 \mathrm{~mL}$ do ácido cítrico, durante 90 segundos.

Após a finalização da primeira fase, os espécimes foram removidos dos dispositivos palatinos e houve um período de wash-out (15 dias). Novos fragmentos foram fixados nos dispositivos palatinos e foi iniciada a segunda fase, na qual os voluntários foram então cruzados em relação aos tratamentos.

O controle do biofilme foi realizado pela aplicação de uma gota de clorexidina a 0,2\% em cada espécime, no início e no final de cada dia, por um período de um minuto, com enxágue posterior em água corrente (West et al., 1998).

\subsection{Método de Coloração Histoquímica}

Finalizada a fase intrabucal, as amostras da dentina radicular de cada grupo experimental foram individualmente imersas em $1 \mathrm{~mL}$ de uma solução aquosa de sulfato de cobre a 10\% (Vetec Química Fina Ltda, Duque de Caxias, RJ, Brasil), por 30 minutos. A seguir, os fragmentos foram secos em papel absorvente e imersos em $1 \mathrm{~mL}$ de solução alcoólica de ácido rubeânico a 1\%, por 30 minutos (Fluka, Sigma- 
Aldrich, Steinhein, Germany). Após a coloração, os espécimes foram lavados com água destilada por 15 segundos, secos e mantidos individualmente em um recipiente vedado, com algodão embebido em amônia, por 7 dias. Um protocolo de coloração histoquímica semelhante foi descrito por Carrasco et al. (2003) e validado para lesões de erosão por Turssi et al. (2005).

\subsection{Avaliação da permeabilidade}

As amostras foram seccionadas transversalmente em cortadeira de precisão (Isomet 1000, Buehler) refrigerada à água. Da região delimitada, foram obtidas três secções com espessura média de $400 \mu \mathrm{m}$ que foram reduzidas com lixa d'água em

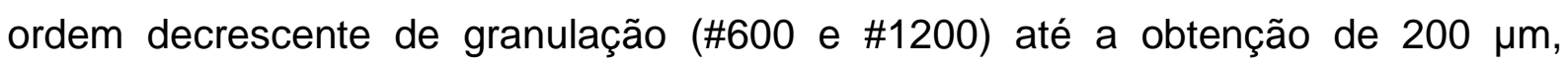
aproximadamente.

As imagens para as análises da permeabilidade foram realizadas com câmera fotográfica digital (Axiocam MRc, Carl Zeiss, Jena, Alemanha), acoplada ao microscópio óptico (Axiostar Plus, Carl Zeiss, Jena). A avaliação da permeabilidade foi realizada utilizando-se o software (Axiovision 4.8, Carl Zeiss, Alemanha) para captura e análise de imagem, o qual permitiu a mensuração da extensão da penetração dos íons cobre na dentina radicular erodida. Em cada um dos três cortes obtidos para cada unidade experimental, foram realizadas três avaliações de maior penetração da solução traçadora. A média desses valores representou a permeabilidade em cada secção. Para cada espécime foram obtidos nove valores de permeabilidade relativa, calculada de acordo com a fórmula:

\section{Permeabilidade relativa $=\underline{\text { extensão da penetração da solução }}$ espessura da dentina}

\subsection{Análise Estatística}

Após a obtenção dos dados, foi realizado um teste estatístico para verificar a homogeneidade dos dados, que apresentaram distribuição normal. Dessa forma, os dados experimentais foram analisados estatisticamente pelo teste de Análise de Variância (ANOVA), com nível de significância de 5\%. Foi utilizado o teste complementar de Duncan para averiguar a influência da associação do verniz 
fluoretado ao laser de Er:YAG e ao laser de Nd:YAG na permeabilidade da dentina radicular erodida, utilizando-se um modelo in situ. A análise estatística foi realizada com auxílio do software SPSS para Windows, versão 12.0 (SPSS, Inc, Chicago, IL, USA). 


\section{Fluxograma}

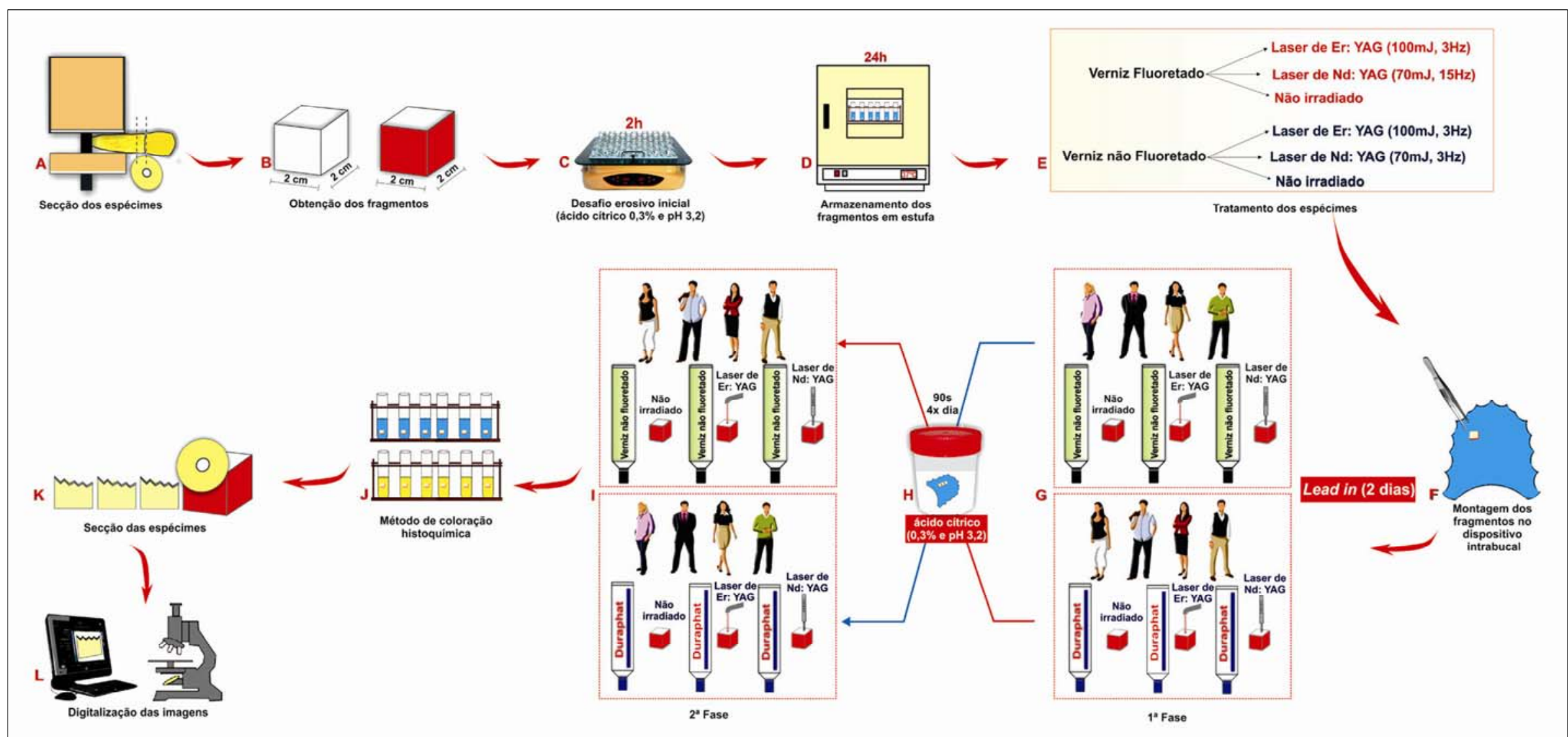

Figura 1. A. Secção dos Espécimes; B. Obtenção dos fragmentos e aplicação do esmalte cosmético; C. Desafio erosivo inicial; D. Armazenamento dos espécimes em estufa; E. Divisão dos espécimes em relação aos tratamentos dentinários; F. Montagem dos fragmentos no dispositivo intrabucal; G. $1^{a}$ Fase do experimento - os voluntários foram divididos em relação aos tratamentos; $\mathbf{H}$. Desafios erosivos sofridos durante a fase intrabucal; I. $2^{\mathrm{a}}$ Fase do experimento- cruzamento dos voluntários em relação aos tratamentos; J. Método de coloração histoquímica; $\mathrm{K}$. Secção dos espécimes; L. Digitalização das imagens e medida da penetração do corante. 
Resultados 


\section{Resultados}

A ANOVA dois critérios e o teste complementar de Duncan revelaram que as amostras tratadas apenas com o verniz fluoretado ou com o mesmo verniz em associação com o laser de Er:YAG ou Nd:YAG não apresentaram diferenças estatísticas significantes em relação à permeabilidade da dentina radicular erodida. A aplicação do verniz não fluoretado, e desse verniz combinado ao laser (Er:YAG ou $\mathrm{Nd}: Y A G)$ também não apresentou diferenças estatisticamente significantes.

Contudo, foi observada uma diferença significativa entre os espécimes tratados com o verniz fluoretado $(p=0,005)$, verniz fluoretado + laser de Er:YAG $(p=0,014)$ e verniz fluoretado + laser de Nd:YAG $(p=0,025)$ em comparação com os que utilizaram o verniz não fluoretado, associado ou não aos lasers.

Tabela 2. Permeabilidade dentinária após sucessivos desafios erosivos para os diferentes grupos experimentais (\%).

\begin{tabular}{|c|c|c|}
\hline Verniz & Fluoretado & Não Fluoretado \\
\hline Er:YAG & $5,66( \pm 1,33)^{\mathrm{Aa}}$ & $8,61( \pm 2,53)^{\mathrm{Ba}}$ \\
\hline $\mathrm{Nd}: Y A G$ & $5,41( \pm 2,04){ }^{\mathrm{Aa}}$ & $7,08( \pm 1,77){ }^{\text {ва }}$ \\
\hline Não Irradiado & $4,56( \pm 2,14)^{\mathrm{Aa}}$ & $7,52( \pm 0,89)^{\mathrm{Ba}}$ \\
\hline
\end{tabular}

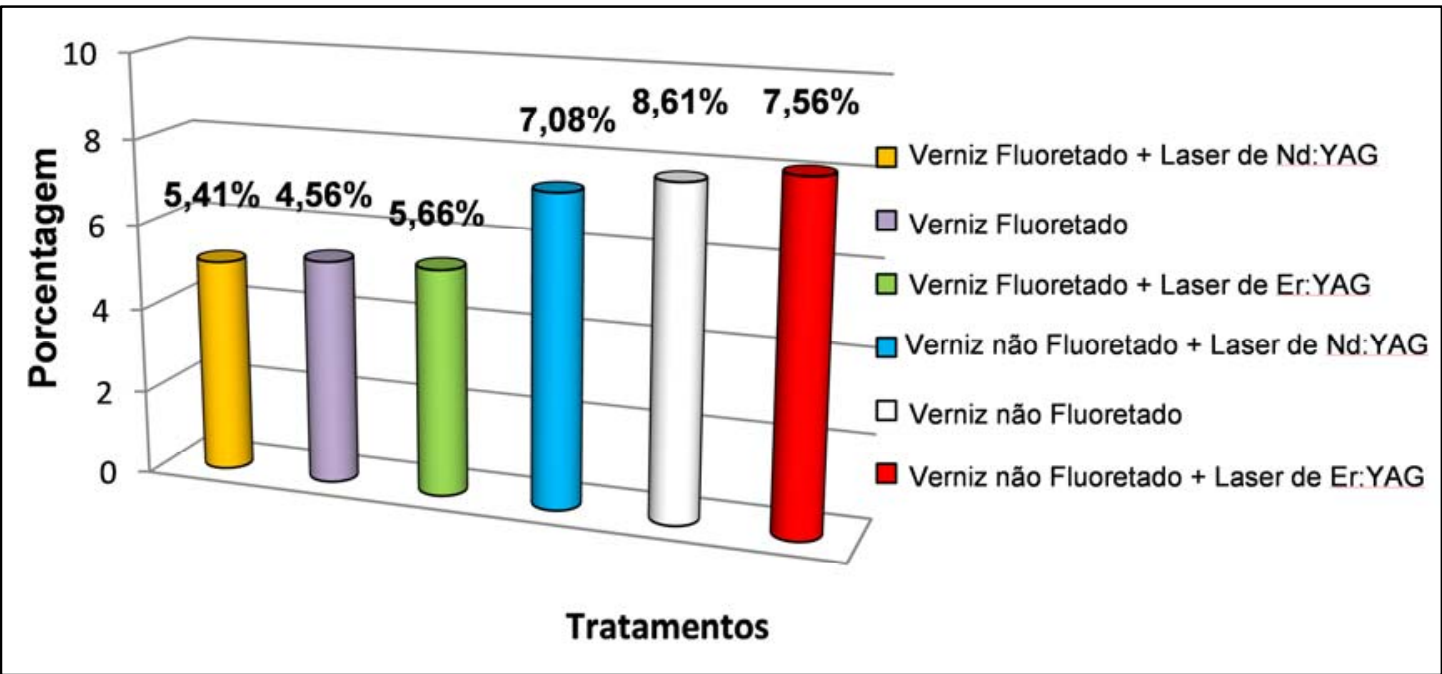

Gráfico 1. Permeabilidade dentinária após sucessivos desafios erosivos para os diferentes grupos experimentais. 
Discussão 


\section{Discussão}

De acordo com a teoria hidrodinâmica (Brännström, 1986, 1992), terapias capazes de promover a oclusão dos túbulos e consequentemente a redução da permeabilidade dentinária são capazes de promover a dessensibilização da dentina (Pashley, 1986). Dessa forma, o verniz fluoretado (Ritter et al., 2006; Merika et al., 2006), o laser de Er:YAG (Birang et al., 2007; Schwarz et al., 2002) e o laser de Nd:YAG (Kara; Orbak, 2009; Birang et al., 2007) vêm sendo utilizados para o tratamento da hipersensibilidade dentinária, com o objetivo de obliterar o diâmetro dos túbulos. Todavia, não há trabalhos na literatura que comparam a ação combinada desses tratamentos.

Neste estudo, foi observada uma diferença estatisticamente significante nos valores de permeabilidade dentinária entre os espécimes tratados com o verniz fluoretado isolado e associado aos lasers (Er:YAG ou Nd:YAG) em comparação aos grupos que utilizaram verniz não fluoretado isolado e associado aos lasers (Er:YAG ou Nd:YAG).

Esse resultado pode ser atribuído à formação da camada de fluoreto de cálcio criada pelo verniz fluoretado (Arends; Schuthof, 1975; Grobler et al., 1983; de Bruyn; Arends, 1987; Magalhães et al., 2008; Magalhães et al., 2010), que poderia ser capaz de ocluir os túbulos dentinários e controlar a permeabilidade da dentina radicular erodida. Em um estudo in situ, Scatolin et al. (2012) verificaram que a utilização de outros compostos fluoretados (dentifrícios) também foi efetiva no controle da permeabilidade da dentina radicular erodida, provavelmente devido à formação dessa mesma barreira (Ganss et al., 2004).

É possível encontrar na literatura trabalhos que relatam um aumento da oclusão dos túbulos dentinários quando se utilizou laser de Nd:YAG combinado ao verniz fluoretado (Lan et al., 1999; Kumar; Mehta, 2005), ou do laser de Er:YAG associado ao fluoreto na forma de gel (Cakar et al., 2008). No presente trabalho, não foi observado nenhum benefício adicional na diminuição da permeabilidade dentinária com associação do verniz fluoretado aos lasers de Er:YAG e Nd:YAG. Entretanto, os nossos resultados não podem ser diretamente comparados com outros estudos, uma vez que não há relatos da avaliação do efeito do laser de Er:YAG combinado ao verniz fluoretado. A aplicação do verniz fluoretado antes da 
irradiação, em nosso trabalho, pode ter atuado como uma barreira mecânica, reduzindo a energia e a temperatura aplicadas na superfície irradiada (Magalhães et al., 2011), o que pode ter alterado a capacidade de absorção dos lasers pela dentina.

Estudos observaram que o laser de Nd:YAG foi capaz de promover fusão e ressolidificação com consequente obliteração total ou parcial dos túbulos dentinários (Lan et al., 2000; Magalhães et al., 2004; Kumar; Mehta, 2005; Gholam et al., 2011). Porém, quando a dentina é exposta a sucessivos desafios erosivos, nota-se uma diminuição dessas obliterações e observa-se até mesmo a presença de túbulos dentinários abertos (Naylor et al., 2006). Esse fato deve ser levado em consideração na avaliação da permeabilidade, uma vez que a capacidade benéfica do laser de Nd:YAG no controle da permeabilidade (Aranha et al., 2005) pode ter sido perdida após os sucessivos desafios ácidos. Magalhães et al. (2008), sugerem que potências entre $0.5 \mathrm{~W}$ e $1.0 \mathrm{~W}$ induziriam fraturas e fissuras na dentina, em vez de fusão e ressolidificação. No entanto, trabalhos que utilizaram a mesma potência (1.0W) que a do presente estudo mostraram redução da permeabilidade (Aranha et al., 2005) e oclusão dos túbulos dentinários (Abed et al., 2011).

Poucos estudos na literatura avaliaram os efeitos do laser de Er:YAG na dentina. Esse laser foi capaz de ocluir os túbulos dentinários e diminuir a permeabilidade, quando simulada uma situação de hipersensibilidade dentinária (Aranha; Eduardo, 2012). Resultados semelhantes foram observados por Aranha et al. (2005), em um estudo no qual a permeabilidade da dentina radicular erodida foi reduzida após a irradiação com o laser de Er:YAG. No presente estudo, o laser de Er:YAG foi capaz de promover um maior controle da permeabilidade quando associado ao verniz fluoretado, utilizando-se densidade de energia de $12.8 \mathrm{~J} / \mathrm{cm}^{2}$. Esse parâmetro parece ter sido adequado, uma vez que foi observada uma redução da permeabilidade dentinária com densidades de energia maiores $\left(19.51 \mathrm{~J} / \mathrm{cm}^{2}\right)$ (Aranha et al., 2005) e menores $\left(5.9 \mathrm{~J} / \mathrm{cm}^{2}\right.$ ) (Aranha; Eduardo, 2012) que a do presente estudo.

Os modelos de estudo in situ representam um estágio intermediário entre os estudos in vitro e clínicos (Clasen; Ogaard, 1999) e são adequado para a avaliação da erosão por permitirem que o processo seja monitorado em um ambiente próximo ao natural, com o desenvolvimento da película adquirida e cuidados com a higiene oral (West et al., 2011). A película adquirida atua como fator de proteção contra a 
erosão dentária (Zero et al., 2006), e uma relação inversa entre o nível de erosão e a espessura da película foi encontrada por Amaech et al. (1999). Em contraste, outros autores relatam que na superfície dentinária a película adquirida formada é capaz de reduzir a perda de cálcio apenas em uma pequena extensão (Wetton et al., 2006; Hara et al., 2006; Hannig et al., 2007).

O ácido cítrico utilizado neste estudo $(0,3 \%, \mathrm{pH} 3,2)$ foi capaz de provocar erosão na dentina (Shellis et al., 2010). Esse processo é dependente do tempo e do pH. Observou-se a dissolução da dentina até mesmo em pH próximo a seis (Vanuspong et al. 2002). A utilização de ácido cítrico (pH 3,2), de acordo com Vanuspong et al. (2002), é capaz de aumentar a erosão da dentina radicular ao longo do tempo, simulando, assim, os desafios ácidos sofridos diariamente. Acredita-se que o desafio erosivo empregado foi agressivo pelo fato de haver uma exposição ao ácido inicial (2 horas). Após os tratamentos, foram realizados novos desafios erosivos (4 vezes por dia/90 segundos), o que seria capaz de provocar maior abertura dos túbulos dentinários (Prati et al., 2003) e consequente maior permeabilidade. Adicionalmente, a camada de cemento foi removida, e a permeabilidade da dentina radicular aumentou após a remoção de 0,2 mm da dentina (Fogel et al., 1988).

Visto que a erosão da dentina pode causar um aumento de sua permeabilidade com consequente desencadeamento clínico da hipersensibilidade dentinária, o presente estudo baseou-se nos parâmetros propostos por Birang et al. (2007), utilizando-se o laser de Nd:YAG (1,0 W) e laser de Er:YAG (100 mJ), que mostraram resultados positivos na redução da hipersensibilidade. Apesar desses parâmetros serem bem estabelecidos por estudos prévios para o tratamento da hipersensibilidade dentinária (Schwarz et al., 2002; Birang et al., 2007), no presente estudo a aplicação do verniz fluoretado combinada à irradiação dos lasers (Er:YAG ou Nd:YAG) não apresentou benefícios adicionais na redução da permeabilidade da dentina radicular erodida. Mais estudos que avaliem esses tratamentos a longo prazo são necessários. 
Conclusão 


\section{Conclusão}

Pode-se concluir que, independentemente da associação ao laser de Er:YAG e ao laser de Nd:YAG, o verniz fluoretado foi capaz de promover a redução da permeabilidade da dentina radicular, in situ, após sucessivos desafios erosivos. Não foi possível observar nenhum efeito adicional entre os tratamentos. 
Referências 


\section{REFERÊNCIAS}

1. Absy EG, Addy M, Adams D. Dentine hypersensitivity. A study of the patency of dentinal tubules in sensitive and non-sensitive cervical dentine. $\mathrm{J}$ Clin Periodontol. 1987; 14:280-4.

2. Abed AM, Mahdian M, Seifi M, Ziaei SA, Shamsaei M. Comparative assessment of the sealing ability of $\mathrm{Nd}$ :YAG laser versus a new desensitizing agent in human dentinal tubules: a pilot study. Odontology. 2011; 99:45-8.

3. Addy M. Clinical aspects of dentine hypersensitivity. Proc Finn Dent Soc. 1992; 88:23-30.

4. Aoki $\mathrm{A}$, Ando $\mathrm{A}$, Watanabe $\mathrm{H}$, Ishikawa. In vitro studies on laser scaling of subgingival calculus with an Er:YAG laser. J Periodontol. 1994; 12: 1097-106.

5. Amaechi BT, Higham SM. Dental erosion: possible approaches to prevention and control. J Dent. 2005; 33:243-52.

6. Amaechi BT, Higham SM, Edgar WM. Techniques for the production of dental eroded lesions in vitro. J Oral Rehabil. 1999; 26:97-102.

7. Aranha AC, Domingues FB, Franco VO, Gutknecht N, Eduardo C de P. Effects of Er:YAG and Nd:YAG lasers on dentin permeability in root surfaces: a preliminary in vitro study. Photomed Laser Surg. 2005; 23:504-8.

8. Aranha AC, Eduardo C de P. (a) In vitro effects of Er,Cr:YSGG laser on dentine hypersensitivity. Dentine permeability and scanning electron microscopy analysis. Lasers Med Sci. 2012; 27:827-34.

9. Apel C, Franzen R, Meister J, Sarrafzadegan H, Thelen S, Gutknecht N. Influence of the pulse duration of an Er:YAG laser system on the ablation threshold of dental enamel. Lasers Med Sci. 2002; 17:253-257.

10. Arends J, Schuthof J. Fluoride content in human enamel after fluoride application and washing - an in vitro study. Caries Res. 1975; 9:363-72.

11. Bartold PM. Dentinal hypersensitivity: a review. Aust Dent J. 2006; 5:212-8.

12. Bartlett DW. The role of erosion in tooth wear: aetiology, prevention and management. Int Dent J. 2005; 55:277-84.

13. Bartlett DW, Fares J, Shirodaria S, Chiu K, Ahmad N, Sherriff M. The association of tooth wear, diet and dietary habits in adults aged 18-30 years old. J Dent. 2011; 39:811-6.

14. Birang R, Poursamimi J, Gutknecht N, Lampert F, Mir M. Comparative evaluation of the effects of Nd:YAG and Er:YAG laser in dentin hypersensitivity treatment. Lasers in Med Sci. 2007; 22:21-4. 
15. Brännström M. The hydrodynamic theory of dentinal pain: sensation in preparations, caries, and the dentinal crack syndrome. J Endod. 1986; 12:4537.

16. Brännström M. Etiology of dentin hypersensitivity. Proc Finn Dent Soc. 1992; 1:7-13.

17. de Bruyn H, Arends J. Fluoride varnishes--a review. J. biol. buccale. 1987; 15:71-82.

18. Cakar G, Kuru B, Ipci SD, Aksoy ZM, Okar I, Yilmaz S. Effect of Er:YAG and $\mathrm{CO} 2$ lasers with and without sodium fluoride gel on dentinal tubules: a scanning electron microscope examination. Photomed Laser Surg. 2008; 26:565-7.

19. Carrasco LD, Fröner IC, Corona SA, Pécora JD. Effect of internal bleaching agents on dentinal permeability of non-vital teeth: quantitative assessment. Dent Traumatol. 2003; 19:85-9.

20. Carvalho R, Freitas P, Otsuki M, Eduardo C, Tagami J. Influence of Er:YAG laser beam angle, working distance and energy density on dentin morphology: a SEM investigation. J Oral Laser Applications. 2005; 5:237-43.

21. Clasen $A B$, Ogaard B. Experimental intra-oral caries models in fluoride research. Acta Odontol Scand .1999; 57:334-41.

22. Colucci V, do Amaral FL, Pécora JD, Palma-Dibb RG, Corona SA. Water flow on erbium:yttrium-aluminum-garnet laser irradiation: effects on dental tissues. Lasers Med Sci. 2009; 24:811-8.

23. Dominici JT, Eleazer PD, Clark SJ, Staat RH, Scheetz JP. Disinfection/sterilization of extracted teeth for dental student use. J Dent Educ. 2001; 65:1278-80.

24. Delbem AC, Bergamaschi M, Sassaki KT, Cunha RF. Effect of fluoridated varnish and silver diamine fluoride solution on enamel demineralization: $\mathrm{pH}-$ cycling study. J Appl Oral Sci. 2006; 14:88-92.

25. Eccles JD, Jenkins WG. Dental erosion and diet. J Dent. 1974; 2: 153-159.

26. Fogel HM, Marshall FJ, Pashley DH. Effects of distance from the pulp and thickness on the hydraulic conductance of human radicular dentin. J Dent Res. 1988; 67:1381- 5.

27. Farmakis ET, Kozyrakis K, Khabbaz MG, Schoop U, Beer F, Moritz A. In vitro evaluation of dentin tubule occlusion by Denshield and Neodymium-doped yttrium-aluminum-garnet laser irradiation. J Endod. 2012; 38:662-6.

28. Ganss C, Klimek J, Brune V, and Schürmann, A. Effects of two fluoridation measures on erosion progression in human enamel and dentine in situ. Caries Res. 2004; 38:561-6. 
29. Ganss C, Klimek J, Schwarz N. A comparative profilometric in vitro study of the susceptibility of polished and natural human enamel and dentine surfaces to erosive demineralization. Arch Oral Biol. 2000; 45:897-902.

30. Gholami GA, Fekrazad R, Esmaiel-Nejad A, Kalhori KA. An evaluation of the occluding effects of Er;Cr:YSGG, Nd:YAG, $\mathrm{CO}_{2}$ and diode lasers on dentinal tubules: a scanning electron microscope in vitro study. Photomed Laser Surg. 2011; 29:115-21.

31. Grobler SR, Ogaard B, Rolla G. Fluoride uptake and retention by sound enamel after in vivo Duraphat application. J Dent Assoc S Afr. 1983; 38:55-8.

32. Gudmundsson K, Kristleifsson G, Theodors A, Holbrook WP. Tooth erosion, gastroesophageal reflux, and salivary buffer capacity. Oral Surg Oral Med Oral Pathol Oral Radiol Endod. 1995; 79:185-9.

33. Hannig C, Becker K, Häusler N, Hoth-Hannig W, Attin T, Hannig M. Arch Protective effect of the in situ pellicle on dentin erosion - an ex vivo pilot study. Arch Oral Biol. 2007; 52:444-9.

34. Hara AT, Ando M, Cury JA, Serra MC, Gonzalez-Cabezas C, Zero DT. Influence of the organic matrix on root dentine erosion by citric acid. Caries Res. 2005; 39:134-8.

35. Hara AT, Ando M, González-Cabezas C, Cury JA, Serra MC, Zero DT. Protective Effect of the Dental Pellicle against Erosive Challenges in situ. J Dent Res. 2006; 85: 612-6.

36. Hibst R, Keller U. Experimental studies of the application of the Er:YAG laser on dental hard substances: Measurement of the ablation rate. Lasers Surg Med. 1989; 9:338-44.

37. Hiraishi N, Sono R, Islam MS, Otsuki M, Tagami J, Takatsuka T Effect of hesperidin in vitro on root dentine collagen and demineralization. J Dent. 2011; 39:391-6.

38. Hoke JA, Burkes EJ Jr, Gomes ED, Wolbarsht ML. Erbium:YAG (2.94 mum) laser effects on dental tissues. J Laser Appl. 1990; 2:61-5.

39. Hsu PJ, Chen JH, Chuang FH, Roan RT. The combined effect of fluoridecontaining desensitizer and Nd:YAG laser irradiation on human dentinal tubules: an in vitro study. Kaohsiung J Med Sci. 2006; 22:24-9.

40. Imfeld T. Dental erosion. Definition, classification and links. Eur J Oral Sci. 1996; 104:151-5.

41. Kara C, Orbak R. Comparative evaluation of Nd:YAG laser and fluoride varnish for the treatment of dentinal hypersensitivity. J Endod. 2009; 35:971-4. 
42. Kleter GA, Damen JJ, Everts V, Niehof J, ten Cate JM. The influence of the organic matrix on demineralization of bovine root dentin in vitro. J Dent Res 1994; 73: 1523-9.

43. Kumar NG, Mehta DS. Short-term assessment of the Nd:YAG laser with and without sodium fluoride varnish in the treatment of dentin hypersensitivity--a clinical and scanning electron microscopy study. J Periodontol. 2005; 76:11407.

44. Lan $\mathrm{WH}$, Chen $\mathrm{KW}$, Jeng JH, Lin $\mathrm{CP}$, Lin SK. A comparison of the morphological changes after $\mathrm{Nd}-\mathrm{YAG}$ and $\mathrm{CO} 2$ laser irradiation of dentin surfaces. J Endod. 2000; 26:450-3.

45. Lan WH, Liu HC, Lin CP. The combined occluding effect of sodium fluoride varnish and $\mathrm{Nd}$ :YAG laser irradiation on human dentinal tubules. J Endod. 1999; 25:424-6.

46. Lussi A, Jaeggi T, Zero D. The role of diet in the aetiology of dental erosion. Caries Res. 2004; 38:34-44.

47. Lussi A, Megert B, Shellis RP, Wang X. Analysis of the erosive effect of different dietary substances and medications. Br J Nutr. 2012; 107:252-62.

48. Magalhães AC, Wiegand A, Rios D, Honório HM, Buzalaf MA. Insights into preventive measures for dental erosion. J Appl Oral Sci. 2009; 17:75-86.

49. Magalhães AC, Levy FM, Rios D, Buzalaf MA. Effect of a single application of $\mathrm{TiF}(4)$ and $\mathrm{NaF}$ varnishes and solutions on dentin erosion in vitro. J Dent. 2010; 38:153-7.

50. Magalhães MF, Matson E, de Rossi W, Alves JB. A morphological in vitro study of the effects of $\mathrm{Nd}$ :YAG laser on irradiated cervical dentin. Photomed Laser Surg. 2004; 22:527-32.

51. Magalhães AC, Rios D, Machado MA, Da Silva SM, Lizarelli R de F, Bagnato VS, Buzalaf MA. Effect of $\mathrm{Nd}$ :YAG irradiation and fluoride application on dentine resistance to erosion in vitro. Photomed Laser Surg. 2008; 26:559-63.

52. Magalhães AC, Romanelli AC, Rios D, Comar LP, Navarro RS, Grizzo LT, Aranha AC, Buzalaf MA. Effect of a single application of TiF4 and NaF varnishes and solutions combined with $\mathrm{Nd}$ :YAG laser irradiation on enamel erosion in vitro. Photomed Laser Surg. 2011; 29:537-44.

53. Martens LC. Laser physics and a review of laser applications in dentistry for children. Eur Arch Paediatr Dent. 2011; 12:61-7.

54. McCarthy R. Dental erosion--current perspectives for general practice. J Ir Dent Assoc. 2012; 58:241-4. 
55. McKnight-Hanes C, Whitford GM. Fluoride release from three glass ionomer materials and the effects of varnishing with or without finishing. Caries Res. 1992; 26:345-50.

56. Merika K, HeftitArthur F, Preshaw PM. Comparison of two topical treatments for dentine sensitivity. Eur J Prosthodont Restor. 2006; 14:38-41.

57. Meurman JH, Drysdale T, Frank RM. Experimental erosion of dentin. Scand J. Dent Res. 1991; 99:457-62.

58. Meurman $\mathrm{JH}$, ten Cate JM. Pathogenesis and modifying factors of dental erosion. Eur J Oral Sci. 1996; 104:199-206.

59. Millward A, Shaw L, Harrington E, Smith AJ. Continuous monitoring of salivary flow rate and $\mathrm{pH}$ at the surface of the dentition following consumption of acidic Caries Res. 1997; 31:44-9.

60. Naylor F, Aranha, AC, Eduardo, CP, Arana-Chavez, VE, Sobral, MA.P. Micromorphological analysis of dentinal structure after irradiation with Nd:YAG laser and immersion in acidic beverages. Photomed Laser Surg. 2006; 24:74552.

61. Orchardson R, Collins WJ. Clinical features of hypersensitive teeth. Br Dent J. $1987 ; 162: 253-6$.

62. Parker S. Verifiable CPD paper: introduction, history of lasers and laser light production. Br Dent J. 2007; 202:21-31.

63. Pashley $\mathrm{DH}$. Dentin permeability, dentin sensitivity, and treatment through tubule occlusion. J Endod. 1986; 12:465-74.

64. Prati C, Montebugnoli L, Suppa P, Valdrè G, Mongiorgi R. Permeability and morphology of dentin after erosion induced by acidic drinks. J Periodontol. 2003; 74:428-36.

65. Ritter A, Dias WL, Miguez P, Caplan, DJ, Swift EJ. Treating cervical dentin hypersentivity with fluoride varnish: a randomized clinical study. J Am Dent Assoc. 2006; 137:1013-20.

66. Scatolin RS, Galo R, Corona SA. In Situ Effect of Dentifrices Associated to $\mathrm{CO}(2)$ Laser in the Permeability of Eroded Root Dentin. Photomed Laser Surg. 2006. 2012; 30:573-8.

67. Sauro S, Gandolfi MG, Prati C, Mongiorgi R. Oxalate-containing phytocomplexes as dentine desensitizers: an in vitro study. Arch Oral Biol. 2006; 51:655-64.

68. Scheutzel P. Etiology of dental erosion--intrinsic factors. Eur J Oral Sci. 1996; 104:178-90. 
69. Shellis RP, Barbour ME, Jones SB, Addy $M$. Effects of $\mathrm{pH}$ and acid concentration on erosive dissolution of enamel, dentine, and compressed hydroxyapatite. Eur J Oral Sci. 2010; 118:475-82.

70. Schwarz F, Arweiler N, Georg T, Reich E. Desensitizing effects of an Er:YAG laser on hypersensitive dentine. J Clin Periodontol. 2002; 29:211-5.

71. Stabholz A, Zeltser R, Sela M, Peretz B, Moshonov J, Ziskind D, Stabholz A. The use of lasers in dentistry: principles of operation and clinical applications. Compend Contin Educ Dent. 2003; 24:935-48.

72. Stabholz A; Sahar-Helft S; Moshonov J. Lasers in endodontics. Dent Clin N Am 2004; 48:809-32.

73. Sunakawa M, Tokita Y, Suda H. Pulsed Nd:YAG Laser Irradiation of the Tooth Pulp in the Cat: II. Effect of Scanning Lasing. Lasers Surg Med 2000; 26:47784.

74. Toro MJ, Lukantsova LL, Williamson M, Hinesley R, Eckert GJ, Dunipace AJ. In vitro fluoride dose-response study of sterilized enamel lesions. Caries Res. 2000; 34:246-53.

75. Turssi, CP, Alves, VD, Serra Suitability of bovine root dentin for studies on permeability of erosion lesions. Caries Res. 2005; 39:287-340.

76. Turssi CP, Messias DF, Corona SM, Serra MC. Viability of using enamel and dentin from bovine origin as a substitute for human counterparts in an intraoral erosion model. Braz. Dent. J. 2010; 21:332-6.

77. Van As G. Erbium lasers in dentistry. Dent Clin North Am. 2004; 48:1017-59.

78. Vanuspong W, Eisenburger M, Addy M. Cervical tooth wear and sensitivity: erosion, softening and rehardening of dentine; effects of $\mathrm{pH}$, time and ultrasonication. J Clin Periodontol. 2002; 29:351-7.

79. West NX, Davies M, Amaechi BT. In vitro and in situ erosion models for evaluating tooth substance loss. Caries Res. 2011; 45:43-52.

80. West NX, Maxwell A, Hughes JA, Parker DM, Newcombe RG, Addy M. A method to measure clinical erosion: the effect of orange juice consumption on erosion of enamel. J Dent. 1998; 26:329-35.

81. Wetton S, Hughes J,West N, Addy M. Exposure time of enamel and dentin to saliva for protection against erosion: a study in vitro. Caries Res. 2006; 40:2137.

82. Zero DT, Hara AT, Kelly SA, González-Cabezas C, Eckert GJ, Barlow AP, Mason SC. Evaluation of a desensitizing test dentifrice using an in situ erosion remineralization. J Clin Dent. 2006; 17:112-6. 
83. Zero DT. Etiology of dental erosion--extrinsic factors. Eur J Oral Sci. 1996; 104:162-77 
Anexo 


\section{FACULDADE DE \\ ODONTOLOGIA DE RIBEIRÃO PRETO/ FORP/ USP}

\section{PROJETO DE PESQUISA}

\begin{tabular}{ll}
\hline Título: & Avaliação in situ do Efeito do Laser de Er:YAG e Nd:YAG Associados ao Verniz Fluoretado na \\
& Permeabilidade da Dentina Radicular Erodida
\end{tabular}

Área Temática:

Versão: 2

CAAE: $\quad 02417912.2 .0000 .5419$

Pesquisador: Mariana Alencar Nemezio

Instituição: Faculdade de Odontologia de Ribeirão Preto/ FORPI USP

\section{PARECER CONSUBSTANCIADO DO CEP}

\begin{tabular}{lc}
\hline Número do Parecer: & 92.188 \\
Data da Relatoria: & $21 / 08 / 2012$
\end{tabular}

Apresentação do Projeto:

Projeto adequadamente construi¿do.

\section{Objetivo da Pesquisa:}

Avaliar in situ o feito da associac $\_$a $\_$o do verniz fluoretado aos lasers de Er:YAG e Nd:YAG na dentina radicular apo ¿s sucessivos desafios ácidos por meio da análise da permeabilidade. Supondo-se que a concentração de ions flúor no substrato dentinário, ou alterações na organização microestrutural desse substrato pelo uso dos lasers, poderão reduzir a permeabilidade dentinária.

\section{Avaliação dos Riscos e Beneficios:}

Riscos:

Os voluntários poderão sentir um leve desconforto pelo uso do aparelho removivel, que será amenizado com ajuste criterioso do dispositivo. Porém, este possivel desconforto é totalmente suportável e não acarreta risco à saúde do voluntário.

Beneficios:

Os voluntários receberão beneficios indiretos, por meio de esclarecimento de certas questões relevantes para a odontologia, por meio da divulgaçăo dos resultados no meio científico.

\section{Comentários e Considerações sobre a Pesquisa:}

A pesquisa $e_{\mathcal{L}}$ pertinente. Justifica-se sua realizac $\_$a $\_.$

\section{Considerações sobre os Termos de apresentação obrigatória:}

Adequadamente construídos.

\section{Recomendações:}

Nada a relatar.

Conclusões ou Pendências e Lista de Inadequações:

Pendências atendidas.

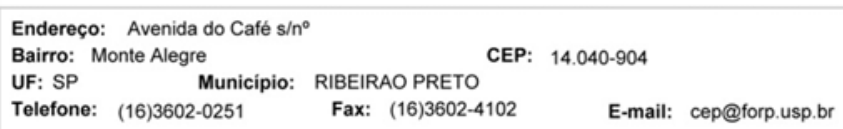




\section{FACULDADE DE \\ ODONTOLOGIA DE RIBEIRÃO \\ PRETO/ FORP/ USP

Situação do Parecer:

Aprovado

Necessita Apreciação da CONEP:

Não

RIBEIRAO PRETO, 06 de Setembro de 2012

Assinado por

JOSÉ TARCÍSIO LIMA FERREIRA

UF: SP Municipio: RIBEIRAO PRETO

CEP: $14.040-904$

Telefone: (16)3602-025 